OPEN ACCESS

Check for updates

\section{Comparative efficacy of interventions for reducing symptoms of depression in people with dementia: systematic review and network meta-analysis}

\author{
Jennifer A Watt, ${ }^{1,2}$ Zahra Goodarzi, ${ }^{3,4,5}$ Areti Angeliki Veroniki, ${ }^{1,6,7}$ Vera Nincic, ${ }^{1}$ Paul A Khan, ${ }^{1}$ \\ Marco Ghassemi, ${ }^{1}$ Yonda Lai, ${ }^{1}$ Victoria Treister, ${ }^{1}$ Yuan Thompson, ${ }^{1}$ Raphael Schneider, $8,9,10$ \\ Andrea C Tricco, ${ }^{1,11}$ Sharon E Straus ${ }^{12,11}$
}

For numbered affiliations see end of the article.

Correspondence to: I A Watt jennifer.watt@utoronto.ca (or @jennannwatt on Twitter: ORCID 0000-0002-5296-6013)

Additional material is published online only. To view please visit the journal online.

Cite this as: $B M / 2021 ; 372:$ n532 http://dx.doi.org/10.1136/bmj.n532

Accepted: 15 February 2021
OBJECTIVE

To describe the comparative efficacy of drug and non-drug interventions for reducing symptoms of depression in people with dementia who experience depression as a neuropsychiatric symptom of dementia or have a diagnosis of a major depressive disorder.

DESIGN

Systematic review and meta-analysis.

\section{DATA SOURCES}

Medline, Embase, the Cochrane Library, CINAHL, PsycINFO, and grey literature between inception and 15 October 2020.

\section{ELIGIBILITY CRITERIA FOR STUDY SELECTION}

Randomised trials comparing drug or non-drug interventions with usual care or any other intervention targeting symptoms of depression in people with dementia.

\section{MAIN OUTCOME MEASURES}

Pairs of reviewers screened studies, abstracted aggregate level data, and appraised risk of bias with the Cochrane risk of bias tool, which facilitated the derivation of standardised mean differences and back transformed mean differences (on the Cornell scale for depression in dementia) from bayesian random effects network meta-analyses and pairwise metaanalyses.

RESULTS

Of 22138 citations screened, 256 studies ( 28483 people with dementia) were included. Missing

\section{ABSTRACT}

\section{WHAT IS ALREADY KNOWN ON THIS TOPIC}

Interest is growing in social prescribing-linking patients with non-drug interventions in their community-to reduce symptoms of depression, isolation, and loneliness

Individual randomised trials have shown that non-drug interventions (eg, exercise) alleviate symptoms of depression in people with dementia

The comparative efficacy of drug and non-drug interventions for reducing symptoms of depression in people with dementia, with or without a diagnosis of a major depressive disorder, is, however, unknown

\section{WHAT THIS STUDY ADDS}

In this systematic review, non-drug approaches were associated with a meaningful reduction in symptoms of depression in people with dementia and without a diagnosis of a major depressive disorder

Drug approaches alone, however, were not more efficacious than usual care data posed the greatest risk to review findings. In the network meta-analysis of studies including people with dementia without a diagnosis of a major depressive disorder who were experiencing symptoms of depression (213 studies; 25177 people with dementia; between study variance 0.23 ), seven interventions were associated with a greater reduction in symptoms of depression compared with usual care: cognitive stimulation (mean difference -2.93 , $95 \%$ credible interval -4.35 to -1.52 ), cognitive stimulation combined with a cholinesterase inhibitor $(-11.39,-18.38$ to -3.93$)$, massage and touch therapy $(-9.03,-12.28$ to -5.88$)$, multidisciplinary care $(-1.98,-3.80$ to -0.16$)$, occupational therapy $(-2.59,-4.70$ to -0.40$)$, exercise combined with social interaction and cognitive stimulation $(-12.37$, -19.01 to -5.36$)$, and reminiscence therapy $(-2.30$, -3.68 to -0.93$)$. Except for massage and touch therapy, cognitive stimulation combined with a cholinesterase inhibitor, and cognitive stimulation combined with exercise and social interaction, which were more efficacious than some drug interventions, no statistically significant difference was found in the comparative efficacy of drug and non-drug interventions for reducing symptoms of depression in people with dementia without a diagnosis of a major heterogeneity precluded network meta-analysis of studies comparing the efficacy of interventions specifically for reducing symptoms of depression in people with dementia and a major depressive disorder (22 studies; 1829 patients).

\section{CONCLUSIONS}

In this systematic review, non-drug interventions were found to be more efficacious than drug interventions for reducing symptoms of depression in people with dementia without a major depressive disorder.

SYSTEMATIC REVIEW REGISTRATION PROSPERO CRD42017050130.

\section{Introduction}

Fifty million people worldwide have a diagnosis of dementia. ${ }^{1}$ About $16 \%$ of people with dementia also have a diagnosis of a major depressive disorder, but $32 \%$ of those with dementia will experience symptoms of depression (as part of the neuropsychiatric symptoms of dementia) without a formal diagnosis of a major depressive disorder. ${ }^{23}$ In people with dementia, symptoms of depression manifest clinically as physical (eg, poor appetite, low energy) and behavioural (eg, depressive disorder. Clinical and methodological 
irritability, social isolation, sadness) signs. ${ }^{45}$ Although those with dementia and symptoms of depression might not fulfil all the criteria of a major depressive disorder, these symptoms nonetheless have an impact on people with dementia and their care givers. ${ }^{6-8}$ Symptoms of depression in people with dementia are associated with adverse health outcomes, including lower quality of life, functional decline, and increased risk of death ${ }^{6-11}$ and are also associated with increased distress, burden, and depression in care givers. ${ }^{78}$

Drug (eg, antidepressants, antipsychotics) and non-drug (eg, reminiscence therapy, exercise) interventions are used to treat both major depressive disorders and symptoms of depression in people with dementia. ${ }^{12-16}$ Increasing evidence of harm associated with antidepressant use in those with dementia (eg, from falls and fractures), and growing interest in social prescribing-linking patients with non-drug interventions in their community-as an effective treatment to combat symptoms of depression, loneliness, and isolation, has led to a renaissance for non-drug interventions. ${ }^{17} 18$ Randomised trials directly comparing the efficacy of drug and nondrug interventions are, however, rare, which creates uncertainty in clinical decision making about selection of optimal evidence based interventions for treating symptoms of depression in people with dementia.

We determined the comparative efficacy of drug and non-drug interventions for reducing symptoms of depression in people with dementia who were experiencing depression as a neuropsychiatric symptom of dementia or had a diagnosis of a major depressive disorder. Network meta-analysis (NMA) was used to fill this critical knowledge gap created by a paucity of head-to-head randomised controlled trials.

\section{Methods}

We registered and published our protocol, which contains details of the literature search strategy. ${ }^{19}$ Our systematic review and NMA manuscript is written in accordance with the Preferred Reporting Items for Systematic Reviews and Meta-analyses (PRISMA) extension statement for reporting systematic reviews incorporating NMA. ${ }^{20}$

\section{Data sources and searches}

We searched Medline, Embase, the Cochrane Library, CINAHL, and PsycINFO for citations published in any language from inception to 15 October $2020 .{ }^{19}$ We also searched grey literature and reviewed reference lists of included studies and related systematic reviews. ${ }^{19}$

\section{Study selection}

Eligible studies for inclusion were randomised controlled trials of drug and non-drug interventions used to treat symptoms of depression in people with dementia experiencingdepressionasaneuropsychiatric symptom of dementia or with a diagnosis of a major depressive disorder. Dementia (eg, medical history of dementia or Diagnostic and Statistical Manual of Mental Disorders, fifth edition (DSM-V)) and major depressive disorder (eg, DSM-V) were defined by study authors. ${ }^{6}$ Eligible drug interventions required final approval from the US Food and Drug Administration or Health Canada, as of our literature search date. Eligible comparators included usual care, placebo, or another drug and non-drug intervention. Studies reporting symptoms of depression using any outcome measure (eg, geriatric depression scale or Cornell scale for depression in dementia) were considered suitable for inclusion (see supplementary table 1 ). ${ }^{45}$ After pilot testing, pairs of reviewers (JAW, ZG, VN, PAK, MG, YL, VT, YT, RS) independently screened all citations and full text articles. No language restrictions were applied. Discrepancies in study inclusion were resolved by deliberation within the reviewer pairs or with input from a third reviewer.

\section{Data abstraction and quality assessment}

Pairs of reviewers (JAW, ZG, VN, PAK, MG, YL, YT, RS) abstracted aggregate level data from each included full text article and appraised each randomised controlled trial using the Cochrane risk of bias tool. ${ }^{21}$ For studies that reported two or more outcome measures for the same outcome, we established a hierarchy for determining the data to be abstracted. The Cornell scale for depression in dementia was the most commonly reported scale, followed by the geriatric depression scale and then the neuropsychiatric inventory-depression subscale. ${ }^{45}$ The Cornell scale for depression in dementia was preferentially abstracted, when reported. If this scale was not reported, but the geriatric depression scale or neuropsychiatric inventory-depression subscale was reported, we preferentially abstracted these scales before others. In one case we preferentially abstracted the geriatric depression scale as opposed to the neuropsychiatric inventory-depression subscale. ${ }^{22}$ Otherwise, in five cases we preferentially abstracted the MontgomeryÅsberg depression rating scale, Hamilton depression rating scale, major depression rating scale, and Sandoz clinical assessment-geriatric-depressed mood scale. ${ }^{23-27}$ We contacted study authors for additional information about the study methods and reported outcomes. Discrepancies about data abstraction and quality assessment were resolved by deliberation within reviewer pairs or with input from a third reviewer.

\section{Data synthesis and analysis}

Two clinicians (JAW and ZG) coded all interventions according to the intervention or interventions described by study authors-that is, if the authors named an intervention as usual care but the intervention included providing educational materials to care givers in addition to usual care then the intervention was coded as "care giver education" (see fig 1 and supplementary table 2 for node definitions). Usual care was defined as appropriate access to healthcare (eg, doctor or nurse practitioner visits) and social care (eg, support for activities of daily living, such as bathing), based on patient needs and preferences. A placebo was defined 
as an inert intervention that was otherwise identical to an active comparator (eg, pill, sham intervention).

We assessed network connectivity using a network diagram (STATA, version 15.1). ${ }^{28}$ Network transitivity was assessed by visual inspection of a table containing categorised study characteristics: mean study duration, mean patient age, mode proportion of women $(\geq 50 \%$ or $<50 \%$ ), mode study setting (eg, nursing home or clinic), mode dementia type, mode outcome measure reported, mode severity of dementia, and mode of two items from the risk of bias assessment (incomplete outcome data and blinding of outcome assessment). When two risk of bias categories had the same number of randomised controlled trials (eg, two trials were at low risk of bias from missing data and two were at high risk of bias from missing data), we reported the risk of bias category associated with the greater risk of bias.

We conducted a bayesian random effects NMA in OpenBUGS, version 3.2.3. ${ }^{29}$ When more than one study existed for a treatment comparison, we conducted bayesian random effects pairwise metaanalysis. In these models, we assumed a common within network heterogeneity variable between studies and between data types (ie, contrast based or arm based data) because all interventions were aimed at alleviating similar symptoms in people with dementia. We chose random effects models because we anticipated between study clinical and methodological heterogeneity. Informative prior distributions were implemented for all between study heterogeneity variables $\left(\log \left(\tau^{2}\right) \sim \mathrm{t}(-3.85,1.932,5)\right) .^{30}$ Vague prior distributions were implemented for trial baselines and treatment effects (normal $(0,1000)$ ). Because several different scales were used across studies, we report outcomes as posterior standardised mean differences with 95\% credible intervals and predictive intervals. We back transformed standardised mean differences to mean differences, measured on the Cornell scale for depression in dementia, by multiplying the pooled standard deviation (derived from baseline mean Cornell scale for depression in dementia values of treatment arms in parallel randomised controlled trials that reported symptoms of depression measured with the scale) by each standardised mean difference. ${ }^{31}$ We compared mean differences with a minimum clinically important difference derived using a distribution based approach. ${ }^{31}$ To approximate the minimum clinically important difference, we derived estimates at 0.4 and 0.5 standard deviations of the pooled standard deviation. ${ }^{31}$ We ranked treatments using surface under the cumulative ranking curve values and accounted for their uncertainty in interpretation. Global inconsistency was assessed by comparing deviance and deviance information criterion statistics between consistency and inconsistency models. ${ }^{32}$ The loop specific approach was used to assess local inconsistency in each closed network loop. ${ }^{33}$ We planned to conduct subgroup analyses based on the following effect modifiers: study setting (residence in a nursing home or assisted living facility versus community or clinic setting), mean age of study population ( $\geq 80$ years or $<80$ years), proportion of women $(\geq 50 \%$ or $<50 \%)$, whether standardised criteria were used to diagnose dementia, history of Alzheimer's disease, study size (omitting studies with $<50$ patients enrolled), dementia severity (mildmoderate or moderate-severe), and intervention duration ( $\geq 11$ weeks or $<11$ weeks). We also planned to conduct sensitivity analyses based on two components of the quality assessment that posed the greatest risk to the validity of study findings: missing outcome data and blinding of outcome assessment. However, additional analyses were possible only in these NMAs of interventions that were connected: standardised

\section{Cognitive stimulation}

Structures therapy (eg, one or two sessions per week, for a defined number of hours) with sessions aimed at promoting cognitive function (eg, orientation, reminiscence, art therapy, games)

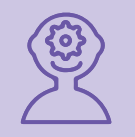

Environmental modification

Any modification to the living environment or place where care is provided

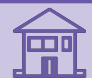

Massage and touch therapy

Any activity involving massage, acupressure, or therapeutic touch

\section{Occupational therapy}

Case management or activities to enhance functional independence, delivered by an occupational therapist

\section{Social interaction}

Interactions with caregivers or others, beyond the provision of usual care

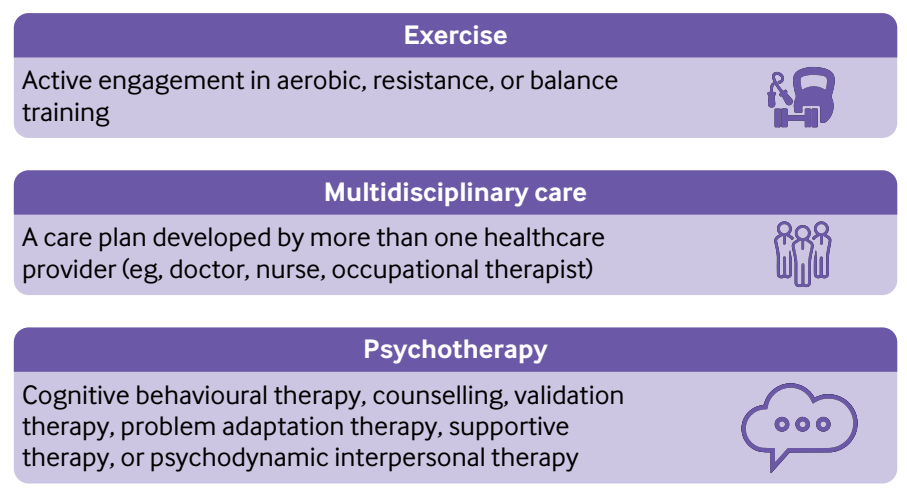

Reminiscence therapy

Any activity to give reminders of a patient's past or family members

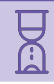

Animal therapy

Any activity involving spending

time with animals

Fig 1 | Descriptions of highly efficacious non-drug interventions in people with dementia 
criteria used to diagnose dementia, mean age of study population $<80$ years, community study setting, mildmoderate dementia severity, intervention duration $\geq 11$ weeks, low risk of bias from missing outcome data, and low or unclear risk of bias from missing outcome data. All other subgroup and sensitivity analyses were presented as pairwise meta-analyses. We completed a network meta-regression based on study publication year. A sensitivity analysis was conducted using a weakly informative prior distribution for between study standard deviation $(\tau \sim \mathrm{N}(0,1), \tau>0)$ in our primary analysis. A comparison adjusted funnel plot was used to assess small study effects, where treatments were ordered by expected efficacy (eg, we would expect reminiscence therapy to be more efficacious than usual care) (STATA, version 15.1).28

\section{Patient and public involvement}

Twelve dementia care partners (nurses, allied health professionals, doctors, and a care giver) participated in an outcome prioritisation exercise. ${ }^{19}$ They independently ranked commonly reported neuropsychiatric symptoms (eg, aggression, agitation, depression, sleep disturbances) in descending order of importance. ${ }^{19} 31$ These care partners selected change in symptoms of depression as an outcome of interest; therefore, our systematic review and NMA compares the efficacy of interventions for reducing symptoms of depression in people with dementia. ${ }^{19}$

\section{Results}

Overall, 22138 citations and 3542 full text articles were screened (fig 2) and 256 articles (28483 people with dementia) included in the systematic review (see supplementary references). Of 29 study authors emailed, 12 responded (41\%): two provided additional data and one clarified study methods. ${ }^{34-36}$ The Cornell scale for depression in dementia was the most reported outcome measure (table 1 and supplementary table 1 ). Most studies enrolled at least $50 \%$ of women and the mean age in most studies was at least 70 years. Studies were most often conducted in community and clinic settings (table 1 and supplementary tables 3a, 3b, 4a, and $4 \mathrm{~b})$.

\section{People with dementia without a major depressive disorder}

Two hundred and thirty five studies reported outcomes for interventions that targeted symptoms of depression in people with dementia without a diagnosis of a major depressive disorder. Of these studies, 213 (25177 people with dementia) were included in pairwise meta-analysis and NMA. The network contained 61 connected intervention nodes: $70 \%$ of direct treatment comparisons involved usual care or placebo (fig 3). There were 45 triangular loops and seven quadratic loops. In most treatment comparisons, studies assessed symptoms of depression using the Cornell scale for depression in dementia and enrolled more women than men. Non-drug interventions were studied in $70 \%$ of trials. Nine studies compared the efficacy of an antidepressant with placebo and two studies compared the efficacy of an antidepressant with an antipsychotic. ${ }^{12} 1325$ 37-43 Risk of bias from missing data and blinding of outcome assessors posed the greatest risk to review findings: $42 \%$ of randomised controlled trials were at high risk of bias from missing data and $37 \%$ of trials were at unclear or high risk of bias from lack of assessor blinding (see supplementary table $5 \mathrm{a}$ and figure $1 \mathrm{a}$ ). Differences were found in effect modifiers across 94 direct treatment comparisonsnamely in terms of study setting, intervention duration, type of dementia, dementia severity, and risk of bias from missing data and lack of assessor blinding (see supplementary table 6). Standard deviation values associated with baseline mean Cornell scale for depression in dementia scores were included from 70 randomised controlled trials in the derivation of minimum clinically important differences. The estimated minimum clinically important difference for the Cornell scale for depression in dementia was 2.0 at 0.4 standard deviations and 2.5 at 0.5 standard deviations.

Supplementary table 7 reports the pairwise metaanalysis and NMA outcomes. The between study variance $\left(\tau^{2}\right)$ in the primary NMA was moderate $(0.23$, $95 \%$ credible interval 0.17 to 0.31 ). A consistency rather than an inconsistency model provided a better model fit (see supplementary table 7). Two closed network loops were inconsistent in the primary NMA (2/52 loops, 4\%): usual care-social interactionanimal therapy (inconsistency factor 1.88, 95\% confidence interval 0.93 to 2.84 ) and music therapysocial interaction-cognitive rehabilitation (1.33, 0.08 to 2.58) (see supplementary figure 2a). No evidence was found of small study effects (see supplementary figure 3).

In the primary NMA, cognitive stimulation, cognitive stimulation combined with a cholinesterase inhibitor, exercise combined with social interaction and cognitive stimulation, massage and touch therapy, multidisciplinary care, occupational therapy, and reminiscence therapy were found to be more efficacious than usual care for reducing symptoms of depression in people with dementia without a diagnosis of a major depressive disorder (table 2 and supplementary table 7). In pairwise meta-analysis, animal therapy, exercise, and psychotherapy combined with reminiscence therapy and environmental modification were also found to be more efficacious than usual care for reducing symptoms of depression in people with dementia (table 2 and supplementary table 7). Except for massage and touch therapy, cognitive stimulation combined with a cholinesterase inhibitor, and cognitive stimulation combined with exercise and social interaction, which were found to be more efficacious than some drug interventions, there was no statistically significant difference in the comparative efficacy of drug and non-drug interventions for reducing symptoms of depression in people with dementia without a diagnosis of a major depressive disorder (see supplementary table 7). These findings 


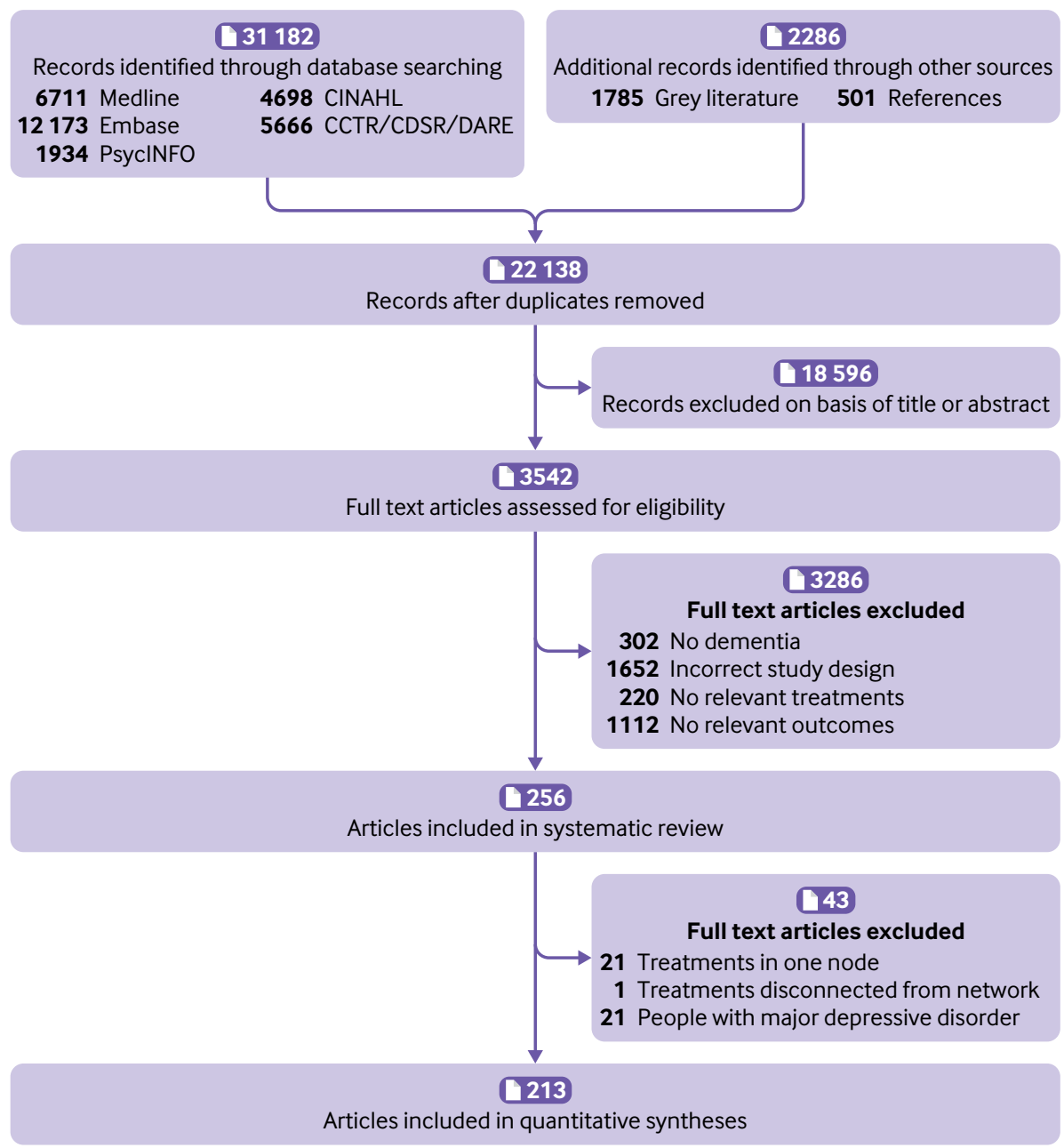

Fig 2 | Flow of studies in the review. CCTR=Cochrane Controlled Trials Register; CDSR=Cochrane Database of Systematic Reviews; DARE=Database of Reviews of Effectiveness

were unchanged when a minimally informative prior was implemented for the heterogeneity variable. Based on surface under the cumulative ranking curve values, the most highly ranked interventions were cognitive stimulation combined with exercise and social interaction $(98.3 \%, 88.3 \%$ to $100 \%)$, cognitive stimulation combined with a cholinesterase inhibitor (98.3\%, 95\% credible interval $86.7 \%$ to $100 \%$ ), and massage and touch therapy $(95.0 \%, 86.7 \%$ to $100 \%)$. When a minimally informative prior was implemented for the heterogeneity variable, the most highly ranked interventions were cognitive stimulation combined with a cholinesterase inhibitor $(98.3 \%, 88.3 \%$ to $100 \%$ ), cognitive stimulation combined with exercise and social interaction $(98.3 \%, 86.7 \%$ to $100 \%)$, and massage and touch therapy $(95.0 \%, 85.0 \%$ to $100 \%)$.

In the NMA of studies with dementia diagnosed using standard criteria (eg, DSM-V), a consistency rather than inconsistency model provided a better model fit, and no inconsistent loops of evidence were found (see supplementary figure $2 \mathrm{~d}$ ). As in the primary NMA, cognitive stimulation, cognitive stimulation combined with a cholinesterase inhibitor, cognitive stimulation combined with exercise and social interaction, massage and touch therapy, multidisciplinary care, occupational therapy, and reminiscence therapy were found to be more efficacious than usual care (table 3 and supplementary tables 8 and 9). In this NMA of studies where dementia was diagnosed using standard criteria, massage and touch therapy, cognitive stimulation combined with a cholinesterase inhibitor, and cognitive stimulation combined with exercise and social interaction were found to be more efficacious than some drug interventions (see supplementary table 8). An antidepressant combined with a cholinesterase inhibitor was found to be more efficacious than care giver support (mean difference -9.2, 95\% credible interval -18.3 to -0.08) in this subgroup of studies, but no statistically significant differences were found when the efficacy of other drug and non-drug interventions were compared (see supplementary table 8).

\section{People with dementia and a major depressive disorder}

Twenty two studies (1829 people with dementia) reported outcomes for interventions aimed at reducing 


\begin{tabular}{|c|c|}
\hline Characteristics & $\%(\mathrm{No})$ of studies $(n=256)$ \\
\hline \multicolumn{2}{|l|}{ Mean age of participants (years): } \\
\hline$<70$ & $5(13)$ \\
\hline $70-74.9$ & $16(40)$ \\
\hline $75-79.9$ & $33(84)$ \\
\hline$\geq 80$ & $42(108)$ \\
\hline Not reported & $4(11)$ \\
\hline \multicolumn{2}{|l|}{ Women enrolled: } \\
\hline $0-49$ & $19(49)$ \\
\hline $50-100$ & $73(186)$ \\
\hline Not reported & $8(21)$ \\
\hline \multicolumn{2}{|l|}{ Dementia type: } \\
\hline Multiple* & $23(58)$ \\
\hline Alzheimer's disease & $41(105)$ \\
\hline Lewy body & $0.4(1)$ \\
\hline Vascular & $1(3)$ \\
\hline Parkinson's disease & $1(2)$ \\
\hline Frontotemporal & $2(4)$ \\
\hline Not reported & $32(83)$ \\
\hline \multicolumn{2}{|l|}{ Dementia severity: } \\
\hline Mild & $12(31)$ \\
\hline Mild or moderate & $42(108)$ \\
\hline Mild, moderate, or severe & $21.5(55)$ \\
\hline Moderate & $2(4)$ \\
\hline Moderate or severe & $10(26)$ \\
\hline Severe & $3(7)$ \\
\hline Not reported & $10(25)$ \\
\hline \multicolumn{2}{|l|}{ Study setting: } \\
\hline Clinic or community & $41(105)$ \\
\hline Hospital & $3(7)$ \\
\hline Nursing home or assisted living & $39.5(101)$ \\
\hline Multiple settings & $9(22)$ \\
\hline Not reported or not clearly reported & $8(21)$ \\
\hline \multicolumn{2}{|l|}{ Duration of study intervention (weeks): } \\
\hline$<11$ & $43(109)$ \\
\hline $11-20$ & $30.5(78)$ \\
\hline $21-30$ & $11(29)$ \\
\hline 130 & $16(40)$ \\
\hline \multicolumn{2}{|l|}{ Measurement tool for depression: } \\
\hline Cornell scale for depression in dementia & $39(100)$ \\
\hline Geriatric depression scale & $23(58)$ \\
\hline Hamilton depression scale & 7 (19) \\
\hline Neuropsychiatric inventory-depression & $15(38)$ \\
\hline Other & $16(41)$ \\
\hline
\end{tabular}

symptoms of depression in people with dementia and a major depressive disorder. The greatest risk to review findings was from missing data: $73 \%$ of studies were at high risk of bias from missing data (see supplementary table $5 \mathrm{~b}$ and figure $1 \mathrm{~b}$ ). Too few studies and anticipated substantial heterogeneity among study characteristics and interventions precluded pairwise meta-analysis or NMA (see supplementary tables $3 \mathrm{~b}$ and $4 \mathrm{~b}$ ). Studies were conducted in both community and noncommunity settings and enrolled participants with Alzheimer's disease or unspecified types of dementia. Drug interventions included mirtazapine, sertraline, venlafaxine, fluoxetine, citalopram, escitalopram, desipramine, imipramine, clomipramine, amitriptyline, and paroxetine. ${ }^{16} 42$ 99-109 Seven randomised controlled trials reported the comparative efficacy of selective serotonin reuptake inhibitors (ie, sertraline, fluoxetine, citalopram, escitalopram) and placebo, with mixed conclusions. ${ }^{1699102103105106108}$ Neither mirtazapine nor venlafaxine were associated with improved symptoms of depression compared with placebo. ${ }^{16100}$ Multidisciplinary care was found to be more efficacious than usual care in one randomised controlled trial, but evidence supporting the efficacy of other non-drug interventions-namely, psychotherapy and exercise-was mixed. ${ }^{110-117}$ Drug strategies for pain management (ie, paracetamol (acetaminophen) or buprenorphine) were not found to be superior to placebo. $^{118}$

\section{Discussion}

Our systematic review and NMA showed that non-drug interventions were as, or more, efficacious than drug interventions for reducing symptoms of depression in people with dementia and without a diagnosis of a major depressive disorder. Ten interventions were found to be more efficacious than usual care in our primary pairwise meta-analyses and NMA: animal therapy, cognitive stimulation, exercise, massage and touch therapy, reminiscence therapy, multidisciplinary care, occupational therapy, cognitive stimulation and a cholinesterase inhibitor, exercise combined with social interaction and cognitive stimulation, and psychotherapy combined with reminiscence therapy and environmental modification. No drug intervention alone was found to be more efficacious than usual care. Intervention rankings suggest that non-drug interventions either alone or in combination with drug interventions are the best interventions for reducing symptoms of depression in people with dementia without a diagnosis of a major depressive disorder. Our findings further suggest a high probability that people with dementia will derive a clinically meaningful benefit from non-drug interventions.

\section{Comparison with other studies}

This systematic review and NMA compared the efficacy of drug interventions with non-drug interventions for reducing symptoms of depression in people with dementia. Previous systematic reviews found potential reductions in symptoms of depression associated with certain non-drug interventions. ${ }^{119} 120$ Another systematic review showed limited and inconsistent evidence of benefit concerning the efficacy of drug interventions for reducing symptoms of depression in people with dementia. ${ }^{121}$ In our NMA we synthesised data for 61 interventions across 213 studies to bring together these two disparate bodies of literature and show the relative ranking of drug and nondrug interventions in terms of efficacy. Our study is important and timely given the growing interest in social prescribing-linking patients with non-drug interventions in their community-as a treatment regimen for mitigating symptoms of depression, loneliness, and social isolation. ${ }^{18}$ We identified efficacious non-drug treatment options (eg, cognitive stimulation, exercise, and reminiscence therapy) that clinicians can prescribe as part of an evidence based treatment plan to reduce symptoms of depression in people with dementia. Our finding that non-drug 


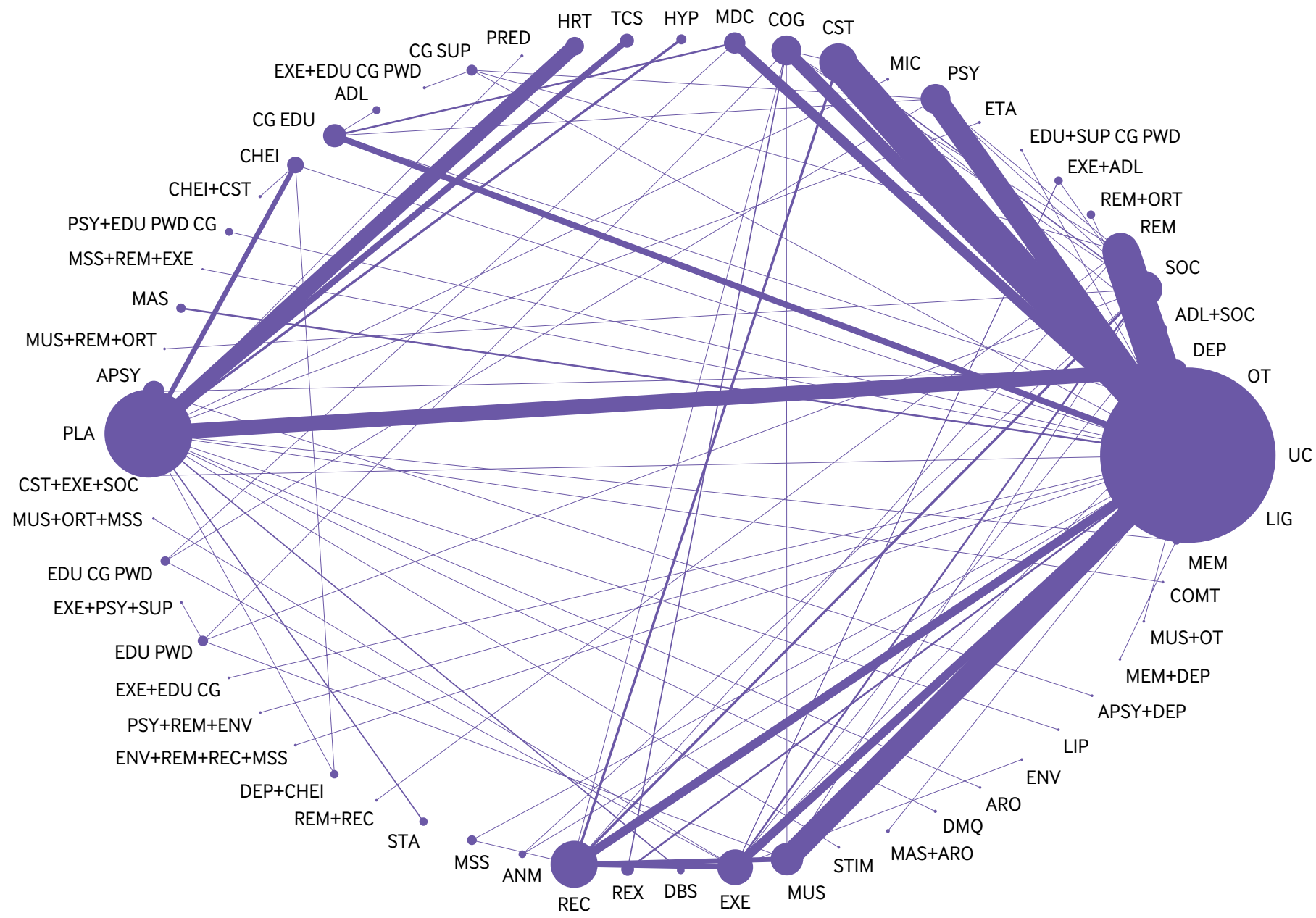

Fig 3 | Network diagram for a network of interventions targeted at reducing symptoms of depression in people with dementia without a major depressive disorder. Nodes represent individual interventions, and nodes connected by lines indicate that the two connected interventions were directly compared in a study. Nodes are weighted by the number of studies that evaluated the treatment, and lines are weighted by the number of studies that evaluated the treatment comparison. $A D L=a c t i v i t i e s$ of daily living modification; $A N M=a n i m a l$ therapy; $A P S Y=a n t i p s y c h o t i c s$, $A R O=$ aromatherapy, $C G$ SUP=care giver support; $C H E I=$ cholinesterase inhibitor; $C O G=$ cognitive rehabilitation; $C O M T=$ catechol-O-methyltransferase inhibitor; $C S T=$ cognitive stimulation; DBS=deep brain stimulation; $D E P=$ antidepressant; $D M Q=$ dextromethorphan-quinidine; EDU+SUP CG $\mathrm{PWD}=$ education and support of person with dementia and care giver; $\mathrm{EDU} C \mathrm{CG}=$ care giver education; $\mathrm{EDU}$ CG PWD=education of care giver

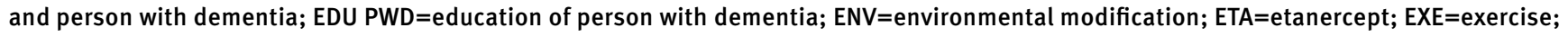

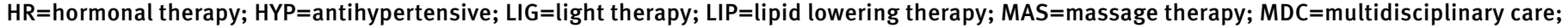
$M E M=$ memantine; $M I C=$ antimicrobial; $M S S=$ multisensory stimulation; $M U S=$ music therapy; $O R T=$ reality orientation; $O T=o c c u p a t i o n a l$ therapy; $P L A=$ placebo; $P R E D=$ prednisone; $P S Y=p s y c h o t h e r a p y ; R E C=$ recreation therapy; $R E X=$ relaxation therapy; $R E M=$ reminiscence therapy; $S O C=s o c i a l$ interaction; STA=mood stabiliser; STIM=stimulant; TCS=transcutaneous stimulation; UC=usual care

and multidisciplinary care approaches alleviate symptoms of depression in people with dementia builds on our recent finding that these approaches also reduce symptoms of aggression and agitation in people with dementia. ${ }^{31}$ However, cost effectiveness, scalability, and sustainability of efficacious non-drug and multidisciplinary interventions for reducing neuropsychiatric symptoms in people with dementia remain unclear and might vary by intervention. ${ }^{122} 123$

Policy implications

Several effective non-drug interventions, including cognitive stimulation, multidisciplinary care, occupational therapy, and exercise are already accessible in some clinical and community settings; however, clinicians, policy makers, health services researchers, and implementation scientists must work together to ensure that all people with dementia have equitable access to these interventions, regardless of sex, geographical location (ie, rural or urban) or ethnicity; to teach patients and care givers about how these interventions can reduce symptoms of depression; and to study the impact of how enrolling patients in programmes that incorporate these interventions reduces symptoms of depression or other related symptoms of loneliness and social isolation. ${ }^{119}$ For example, the National Institute for Health and Care Excellence dementia care guideline recommends cognitive stimulation therapy to improve cognitive function, independence, and wellbeing. ${ }^{124}$ Moreover, 


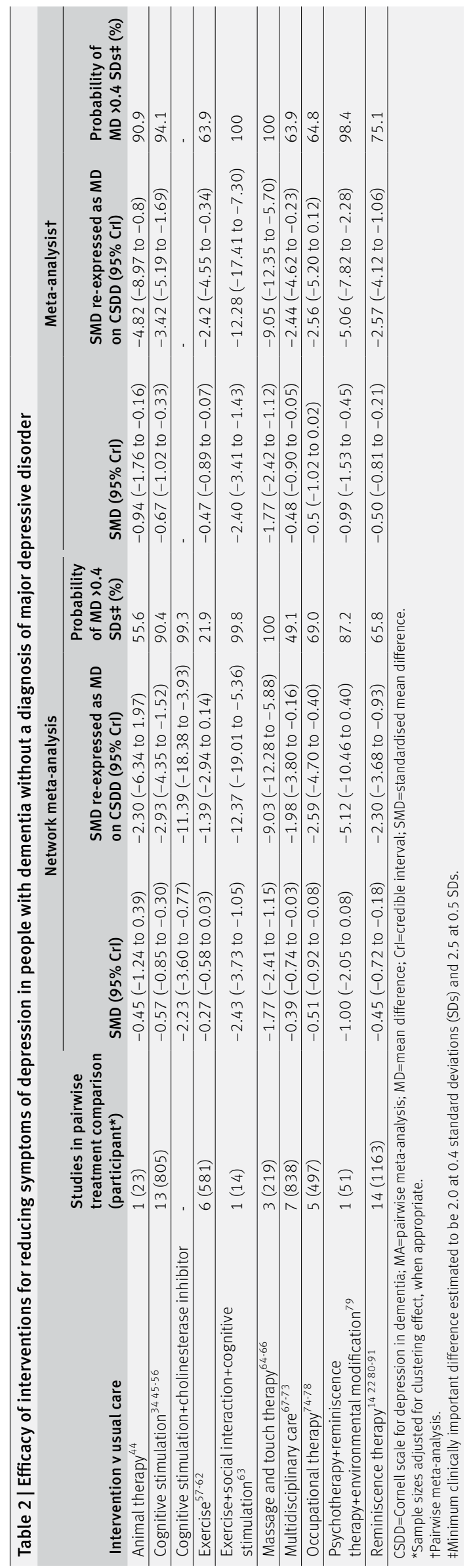

cognitive stimulation therapy is available through National Health Service trusts in England. These cognitive stimulation sessions, encompassing activities to promote mental stimulation, reminiscence, social interaction, and orientation, could be further extended to reduce symptoms of depression in people with dementia. ${ }^{46}$

\section{Strengths and limitations of this review}

Our study has notable strengths. We reviewed more than 3000 full text articles because symptoms of depression, as with other neuropsychiatric symptoms in people with dementia, are often not reported in the title or abstract of articles. We presented our findings as back transformed mean differences on the Cornell scale for depression in dementia (a scale commonly used in clinical practice for capturing symptoms of depression in people with dementia) and probabilities of meeting a threshold for minimum clinically important difference to facilitate knowledge dissemination.

Our study also has limitations. Firstly, although we could derive estimates of intervention efficacy in people with Alzheimer's disease, we could not explore the efficacy of interventions in other types of dementia because studies were too few. Secondly, we could not explore the impact of the severity of depression symptoms on the comparative efficacy of interventions because several different scales were included, not all of which have established thresholds for categorising symptom severity. Thirdly, the risk of bias from missing data was substantial in our systematic review and NMA; however, the number of people with missing data, by treatment group, was not explicitly reported in some studies, which meant we could not assess the impact of missing data on our results. Fourthly, moderate between study heterogeneity in our NMA meant that predictive intervals for some treatment effects were wide and therefore it is difficult to predict the efficacy of an intervention in a subsequent study. Lastly, we did not look at the potential costs or harms associated with implementing drug and non-drug interventions as a treatment for reducing symptoms of depression in people with dementia.

\section{Conclusions}

Our systematic review and NMA comparing the efficacy of drug interventions with non-drug interventions for reducing symptoms of depression in people with dementia showed that non-drug and multidisciplinary approaches are highly efficacious interventions from which people with dementia will derive benefit. Everyone has a role in translating our findings into practice: people with dementia and care givers can speak with clinicians about available non-drug interventions; clinicians can prescribe non-drug interventions to people with dementia and symptoms of depression; and policy makers can support people with dementia, care givers, and clinicians in choosing non-drug interventions by developing health services, systems, and policies that enable implementation. 


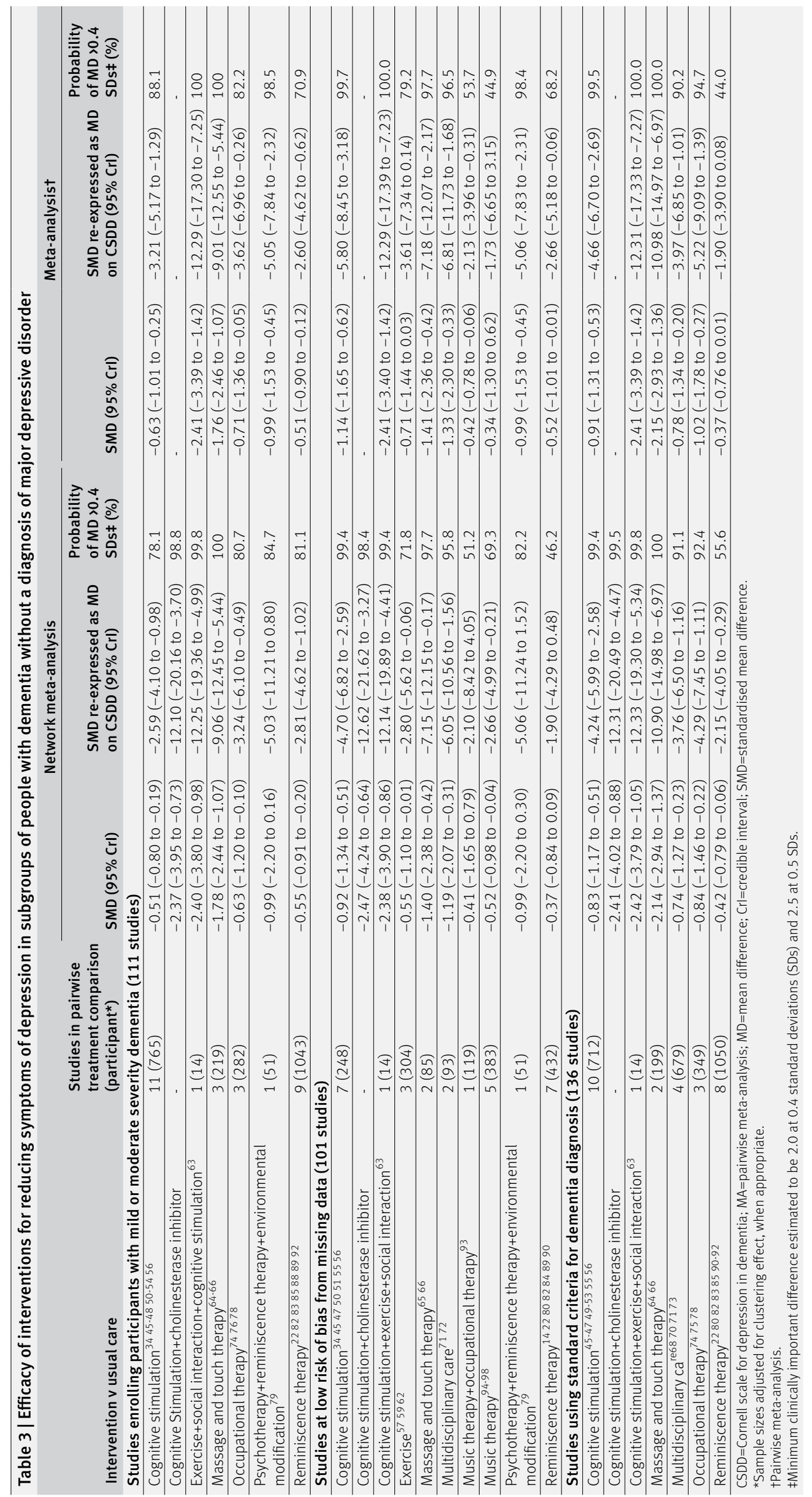




\section{AUTHOR AFFILIATIONS}

${ }^{1}$ Knowledge Translation Program, Li Ka Shing Knowledge Institute, St Michael's Hospital, Toronto, ON, Canada

${ }^{2}$ Division of Geriatric Medicine, Department of Medicine, University of Toronto, Toronto, ON, Canada

${ }^{3}$ Department of Medicine, University of Calgary, Foothills Medical Centre, Calgary, AB, Canada

${ }^{4}$ Hotchkiss Brain Institute, University of Calgary, Calgary, AB, Canada ${ }^{5} \mathrm{O}$ 'Brien Institute of Public Health, University of Calgary, Calgary, AB, Canada

${ }^{6}$ Department of Primary Education, School of Education, University of loannina, loannina, Greece

${ }^{7}$ Institute of Reproductive and Developmental Biology, Department of Surgery and Cancer, Faculty of Medicine, Imperial College, London, UK

${ }^{8}$ Division of Neurology, Department of Medicine, University of Toronto, Toronto, ON, Canada

${ }^{9}$ Institute of Medical Science, University of Toronto, Toronto, ON, Canada

${ }^{10}$ St Michael's Hospital, Toronto, ON, Canada

${ }^{11}$ Institute for Health Policy, Management and Evaluation, University of Toronto, Toronto, ON, Canada

We thank Jessie McGowan for creating our literature search strategy. Contributors: JAW, ZG, ACT, AAV, and SES designed the study. JAW, ZG, VN, PAK, MG, VT, YL, YT, and RS screened articles and abstracted data. JAW, ZG, and AAV conducted data analyses. JAW drafted the first version of the manuscript. All authors contributed to the manuscript's revision and interpretation of findings. JAW is the guarantor. The corresponding author attests that all listed authors meet authorship criteria and that no others meeting the criteria have been omitted.

Funding: This study was funded by the Alberta Critical Care Strategic Clinical Network. The funder had no role in the study design; collection, analysis, and interpretation of data; writing of the report; or decision to submit the article for publication. All authors had full access to study data and can take responsibility for the integrity of the data and accuracy of the data analysis.

Competing interests: All authors have completed the ICMJE uniform disclosure form at www.icmje.org/coi_disclosure.pdf and declare: support from the Alberta Critical Care Strategic Clinical Network; no financial relationships with any organisations that might have an interest in the submitted work in the previous three years; no other relationships or activities that could appear to have influenced the submitted work. ACT is funded by a tier 2 Canada research chair in Knowledge Synthesis. SES is funded by a tier 1 Canada research chair in knowledge translation. AAV is funded by a European Union's Horizon 2020 grant (No 754936)

Ethical approval: Not required.

Data sharing: The full dataset and statistical code will be available upon reasonable request.

The manuscript's guarantor (JAW) affirms that the manuscript is an honest, accurate, and transparent account of the study being reported; that no important aspects of the study have been omitted; and that any discrepancies from the study as originally planned (and, if relevant, registered) have been explained.

Dissemination to participants and related patient and public communities: We will disseminate our results to relevant knowledge user groups (eg, patients, care givers, healthcare managers, and clinicians).

Provenance and peer review: Not commissioned; externally peer reviewed.

This is an Open Access article distributed in accordance with the Creative Commons Attribution Non Commercial (CC BY-NC 4.0) license, which permits others to distribute, remix, adapt, build upon this work non-commercially, and license their derivative works on different terms, provided the original work is properly cited and the use is noncommercial. See: http://creativecommons.org/licenses/by-nc/4.0/.

1 World Alzheimer Report 2018. London; 2018

2 Goodarzi ZS, Mele BS, Roberts DJ, Holroyd-Leduc J. Depression Case Finding in Individuals with Dementia: A Systematic Review and MetaAnalysis. J Am Geriatr Soc 2017;65:937-48. doi:10.1111/igs.14713

3 Asmer MS, Kirkham J, Newton H, et al. Meta-Analysis of the Prevalence of Major Depressive Disorder Among Older Adults With Dementia. J Clin Psychiatry 2018;79:17r11772. doi:10.4088/ JCP.17r11772
4 Alexopoulos GS, Abrams RC, Young RC, Shamoian CA. Cornell Scale for Depression in Dementia. Biol Psychiatry 1988;23:271-84. doi:10.1016/0006-3223(88)90038-8

5 Yesavage JA, Brink TL, Rose TL, et al. Development and validation of a geriatric depression screening scale: a preliminary report. J Psychiatr Res 1982-1983:17:37-49 doi:10.1016/0022-3956(82)90033-4

6 Diagnostic and Statistical Manual of Mental Disorders. 5th ed. American Psychiatric Association, 2013.

7 Fauth EB, Gibbons A. Which behavioral and psychological symptoms of dementia are the most problematic? Variability by prevalence, intensity, distress ratings, and associations with caregiver depressive symptoms. Int J Geriatr Psychiatry 2014;29:263-71. doi:10.1002/ gps.4002

8 Baharudin AD, Din NC, Subramaniam P, Razali R. The associations between behavioral-psychological symptoms of dementia (BPSD) and coping strategy, burden of care and personality style among low-income caregivers of patients with dementia. BMC Public Health 2019;19(Suppl 4):447. doi:10.1186/s12889-019-6868-0

9 Peters ME, Schwartz S, Han D, et al. Neuropsychiatric symptoms as predictors of progression to severe Alzheimer's dementia and death: the Cache County Dementia Progression Study. Am J Psychiatry 2015;172:460-5. doi:10.1176/appi. ajp. 2014.14040480

10 Hurt C, Bhattacharyya S, Burns A, et al. Patient and caregiver perspectives of quality of life in dementia. An investigation of the relationship to behavioural and psychological symptoms in dementia. Dement Geriatr Cogn Disord 2008;26:138-46. doi:10.1159/000149584

11 Kaup BA, Loreck D, Gruber-Baldini AL, et al. Depression and its relationship to function and medical status, by dementia status, in nursing home admissions. Am J Geriatr Psychiatry 2007;15:438-42. doi:10.1097/JGP.0b013e31803c54f7

12 Finkel SI, Mintzer JE, Dysken M, Krishnan KR, Burt T, McRae T. A randomized, placebo-controlled study of the efficacy and safety of sertraline in the treatment of the behavioral manifestations of Alzheimer's disease in outpatients treated with donepezil. Int / Geriatr Psychiatry 2004;19:9-18. doi:10.1002/gps.998

13 Sultzer DL, Gray KF, Gunay I, Wheatley MV, Mahler ME. Does behavioral improvement with haloperidol or trazodone treatment depend on psychosis or mood symptoms in patients with dementia?) Am Geriatr Soc 2001;49:1294-300. doi:10.1046/j.1532$5415.2001 .49256 x$

14 Chang W, Je S. A comparative study on the effect of group reminiscence therapy and group validation therapy for the elderly with dementia. Korean Journal of Gerontological Social Welfare 2008;41:301-25.

15 Boström G, Conradsson M, Hörnsten C, et al. Effects of a highintensity functional exercise program on depressive symptoms among people with dementia in residential care: a randomized controlled trial. Int J Geriatr Psychiatry 2016;31:868-78. doi:10.1002/gps.4401

16 Banerjee S, Hellier J, Dewey M, et al. Sertraline or mirtazapine for depression in dementia (HTA-SADD): a randomised, multicentre, double-blind, placebo-controlled trial. Lancet 2011;378:403-11. doi:10.1016/S0140-6736(11)60830-1

17 Watt JA, Gomes T, Bronskill SE, et al. Comparative risk of harm associated with trazodone or atypical antipsychotic use in older adults with dementia: a retrospective cohort study. CMA/ 2018;190:E1376-83. doi:10.1503/cmaj.180551

18 Drinkwater C, Wildman J, Moffatt S. Social prescribing. BMJ 2019;364:l1285. doi:10.1136/bmj.l1285

19 Watt J, Goodarzi Z, Tricco AC, Veroniki AA, Straus SE. Comparative safety and efficacy of pharmacological and non-pharmacological interventions for the behavioral and psychological symptoms of dementia: protocol for a systematic review and network metaanalysis. Syst Rev 2017;6:182. doi:10.1186/s13643-017-0572-x

20 Hutton B, Salanti G, Caldwell DM, et al. The PRISMA extension statement for reporting of systematic reviews incorporating network meta-analyses of health care interventions: checklist and explanations. Ann Intern Med 2015;162:777-84. doi:10.7326/ M14-2385

21 Higgins JP, Altman DG, Gøtzsche PC, et al, Cochrane Bias Methods Group, Cochrane Statistical Methods Group. The Cochrane Collaboration's tool for assessing risk of bias in randomised trials. BMJ 2011;343:d5928. doi:10.1136/bmj.d5928

22 Hsieh C-J, Chang C, Su S-F, et al. Reminiscence Group Therapy on Depression and Apathy in Nursing Home Residents With Mild-tomoderate Dementia. J Exp Clin Med 2010;2:72-8. doi:10.1016/ S1878-3317(10)60012-5

23 Barnes R, Veith R, Okimoto J, Raskind M, Gumbrecht G. Efficacy of antipsychotic medications in behaviorally disturbed dementia patients. Am J Psychiatry 1982;139:1170-4. doi:10.1176/ ajp.139.9.1170

24 Lawton MP, Van Haitsma K, Klapper J, Kleban MH, Katz IR, Corn J. A stimulation-retreat special care unit for elders with dementing 
illness. Int Psychogeriatr 1998;10:379-95. doi:10.1017/ S104161029800547X

25 Nyth AL, Gottfries CG. The clinical efficacy of citalopram in treatment of emotional disturbances in dementia disorders. A Nordic multicentre study. Br J Psychiatry 1990;157:894-901. doi:10.1192 bjp.157.6.894

26 Ban TA, Morey L, Aguglia E, et al. Nimodipine in the treatment of old age dementias. Prog Neuropsychopharmacol Biol Psychiatry 1990;14:525-51. doi:10.1016/0278-5846(90)90005-2

27 Peabody CA, Davies H, Berger PA, Tinklenberg JR. Desamino-Darginine-vasopressin (DDAVP) in Alzheimer's disease. Neurobiol Aging 1986;7:301-3. doi:10.1016/0197-4580(86)90011-4

28 Chaimani A, Higgins JP, Mavridis D, Spyridonos P, Salanti G. Graphica tools for network meta-analysis in STATA. PLoS One 2013;8:e76654 doi:10.1371/journal.pone.0076654

29 Dias S, Sutton AJ, Ades AE, Welton NJ. Evidence synthesis for decision making 2: a generalized linear modeling framework for pairwise and network meta-analysis of randomized controlled trials. Med Decis Making 2013:33:607-17. doi:10.1177/0272989X12458724

30 Rhodes KM, Turner RM, Higgins JP. Predictive distributions were developed for the extent of heterogeneity in meta-analyses of continuous outcome data. / Clin Epidemiol 2015;68:52-60. doi:10.1016/j.jclinepi.2014.08.012

31 Watt JA, Goodarzi Z, Veroniki AA, et al. Comparative Efficacy of Interventions for Aggressive and Agitated Behaviors in Dementia: A Systematic Review and Network Meta-analysis. Ann Intern Med 2019;171:633-42. doi:10.7326/M19-0993

32 Dias S, Welton NJ, Sutton AJ, Caldwell DM, Lu G, Ades AE. Evidence synthesis for decision making 4: inconsistency in networks of evidence based on randomized controlled trials. Med Decis Making 2013;33:641-56. doi:10.1177/0272989X12455847

33 Veroniki AA, Vasiliadis HS, Higgins JPT, Salanti G. Evaluation of inconsistency in networks of interventions. Int Epidemiol 2013;42:332-45. doi:10.1093/ije/dys222

34 Yamanaka K, Kawano Y, Noguchi D, et al. Effects of cognitive stimulation therapy Japanese version (CST-J) for people with dementia: a single-blind, controlled clinical trial. Aging Ment Health 2013;17:579-86. doi:10.1080/13607863.2013.777395

35 Tse MMY, Lau JL, Kwan R, et al. Effects of play activities program for nursing home residents with dementia on pain and psychological well-being: Cluster randomized controlled trial. Geriatr Gerontol Int 2018;18:1485-90. doi:10.1111/ggi.13509

36 Bass DM, Judge KS, Snow AL, et al. A controlled trial of Partners in Dementia Care: veteran outcomes after six and twelve months. Alzheimers Res Ther 2014;6:9. doi:10.1186/alzrt242

37 Bergh S, Selbæk G, Engedal K. Discontinuation of antidepressants in people with dementia and neuropsychiatric symptoms (DESEP study): double blind, randomised, parallel group, placebo controlled trial. BMJ 2012;344:e1566. doi:10.1136/bmj.e1566

38 Burke WJ, Roccaforte WH, Wengel SP, Bayer BL, Ranno AE, Willcockson NK. L-deprenyl in the treatment of mild dementia of the Alzheimer type: results of a 15-month trial. J Am Geriat Soc 1993:41:1219-25 doi:10.1111/i.1532-5415.1993.tb07306x

39 Choe YM, Kim KW, Jhoo JH, et al. Multicenter, randomized, placebocontrolled, double-blind clinical trial of escitalopram on the progression-delaying effects in Alzheimer's disease. Int / Geriatr Psychiatry 2016;31:731-9. doi:10.1002/gps.4384

40 Freedman M, Rewilak D, Xerri T, et al. L-deprenyl in Alzheimer's disease: cognitive and behavioral effects. Neurology 1998;50:660-8. doi:10.1212/WNL.50.3.660

41 Lebert F, Stekke W, Hasenbroekx C, Pasquier F. Frontotemporal dementia: a randomised, controlled trial with trazodone. Dement Geriatr Cogn Disord 2004:17:355-9. doi:10.1159/000077171

42 Reifler BV, Teri L, Raskind M, et al. Double-blind trial of imipramine in Alzheimer's disease patients with and without depression. Am J Psychiatry 1989;146:45-9. doi:10.1176/ajp.146.1.45

43 Teranishi M, Kurita M, Nishino S, et al. Efficacy and tolerability of risperidone, yokukansan, and fluvoxamine for the treatment of behavioral and psychological symptoms of dementia: a blinded, randomized trial. / Clin Psychopharmacol 2013:33:600-7. doi:10.1097/JCP.0b013e31829798d5

44 Olsen C, Pedersen I, Bergland A, Enders-Slegers MJ, Patil G, Ihlebaek C. Effect of animal-assisted interventions on depression, agitation and quality of life in nursing home residents suffering from cognitive impairment or dementia: a cluster randomized controlled trial. Int J Geriatr Psychiatry 2016;31:1312-21. doi:10.1002/gps.4436

45 Fernández-Calvo B, Rodríguez-Pérez R, Contador I, Rubio-Santorum A, Ramos F. [Efficacy of cognitive training programs based on new software technologies in patients with Alzheimer-type dementia.] Psicothema 2011:23:44-50.

46 Spector A, Thorgrimsen L, Woods B, et al. Efficacy of an evidencebased cognitive stimulation therapy programme for people with dementia: randomised controlled trial. Br J Psychiatry 2003;183:24854. doi:10.1192/bjp.183.3.248
47 Fernández-Calvo B, Contador I, Serna A, et al. El Efecto del Formato de Intervencion Individual o Grupal en la Estimulacion Cognitiva de Pacientes con Enfermedad de Alzheimer. Rev Psicopatol Psicol Clin 2010;15:115-23. doi:10.5944/rppc.vol.15.num.2.2010.4090

48 Folkerts AK, Dorn ME, Roheger M, et al. Cognitive Stimulation for Individuals with Parkinson's Disease Dementia Living in Long-Term Care: Preliminary Data from a Randomized Crossover Pilot Study. Parkinsons Dis 2018;2018:8104673. doi:10.1155/2018/8104673

49 Rexhausen E-M. [Psychosocial care assistants caring for residents with dementia according to $87 \mathrm{~b}$ SGB XI. Emotional and cognitive effects.] Pflege Z 2012;65:418-22

50 Onor ML, Trevisiol M, Negro C, Signorini A, Saina M, Aguglia E. Impact of a multimodal rehabilitative intervention on demented patients and their caregivers. Am J Alzheimers Dis Other Demen 2007;22:261-72. doi:10.1177/1533317507302071

51 Lapre É, Postal V, Bourdel-Marchasson I, et al. Stimulation cognitive et fonctions exécutives dans la maladie d’Alzheimer: une étude pilote. Rev Neuropsychol 2012;4. doi:10.3917/rne.042.0123

$52 \mathrm{Kim} \mathrm{HJ}$, Yang Y, Oh JG, et al. Effectiveness of a community-based multidomain cognitive intervention program in patients with Alzheimer's disease. Geriatr Gerontol Int 2016;16:191-9. doi:10.1111/ggi.12453

53 Orrell M, Yates L, Leung P, et al. The impact of individual Cognitive Stimulation Therapy (iCST) on cognition, quality of life, caregiver health, and family relationships in dementia: A randomised controlled trial. PLoS Med 2017;14:e1002269. doi:10.1371/ journal.pmed.1002269

54 Coen RF, Flynn B, Rigney E, et al. Efficacy of a cognitive stimulation therapy programme for people with dementia. Ir J Psychol Med 2011;28:145-7. doi:10.1017/S0790966700012131

55 Balzotti A, Filograsso M, Altamura C, et al. Comparison of the efficacy of gesture-verbal treatment and doll therapy for managing neuropsychiatric symptoms in older patients with dementia. Int Geriatr Psychiatry 2019;34:1308-15. doi:10.1002/gps.4961

56 Marinho V, Bertrand E, Naylor R, et al. Cognitive stimulation therapy for people with dementia in Brazil (CST-Brasil): Results from a single blind randomized controlled trial. Int J Geriatr Psychiatry 2021;36:286-93.

57 Hoffmann K, Sobol NA, Frederiksen KS, et al. Moderate-to-High Intensity Physical Exercise in Patients with Alzheimer's Disease: A Randomized Controlled Trial. J Alzheimers Dis 2016;50:443-53. doi:10.3233/IAD-150817

58 Chen KM, Kuo CC, Chang YH, Huang HT, Cheng YY. Resistance Band Exercises Reduce Depression and Behavioral Problems of Wheelchair-Bound Older Adults with Dementia: A ClusterRandomized Controlled Trial. J Am Geriatr Soc 2017;65:356-63. doi:10.1111/jgs.14526

59 Vreugdenhil A, Cannell J, Davies A, Razay G. A community-based exercise programme to improve functional ability in people with Alzheimer's disease: a randomized controlled trial. Scand J Caring Sci 2012;26:12-9. doi:10.1111/j.1471-6712.2011.00895.x

60 Rolland Y, Pillard F, Klapouszczak A, et al. Exercise program for nursing home residents with Alzheimer's disease: a 1-year randomized, controlled trial. J Am Geriatr Soc 2007;55:158-65. doi:10.1111/j.1532-5415.2007.01035.x

61 Abd El-Kader SM, Al-jiffri $\mathrm{OH}$. Aerobic exercise improves quality of life, psychological well-being and systemic inflammation in subjects with Alzheimer's disease. Afr Health Sci 2016;16:1045-55. doi:10.4314/ ahs.v16i4.22

62 Huang N, Li W, Rong X, et al. Effects of a Modified Tai Chi Program on Older People with Mild Dementia: A Randomized Controlled Trial. J Alzheimers Dis 2019:72:947-56 doi:10.3233/JAD-190487

63 Maci T, Pira FL, Quattrocchi G, Nuovo SD, Perciavalle V, Zappia M. Physical and cognitive stimulation in Alzheimer Disease. the GAIA Project: a pilot study. Am I Alzheimers Dis Other Demen 2012;27:107-13. doi:10.1177/1533317512440493

64 Todri J, Lena O, Martínez Gil JL. A single blind randomized controlled trial of global postural re-education: Cognitive effects on Alzheimer disease patients. Eur J Psychiatry 2019;33:83-90. doi:10.1016/j. ejpsy.2019.01.001

65 Lu DF, Hart LK, Lutgendorf SK, Oh H, Schilling M. Slowing progression of early stages of AD with alternative therapies: a feasibility study. Geriatr Nurs 2013;34:457-64. doi:10.1016/j. gerinurse.2013.07.003

66 Todri J, Todri A, Lena O. Why Not a Global Postural Reeducation as an Alternative Therapy Applied to Alzheimer's Patients in Nursing Homes? A Pioneer Randomized Controlled Trial. Dement Geriatr Cogn Disord 2019;48:172-9. doi:10.1159/000505397

67 Yang D-l, Li X, Su N, et al. Family medical intervention model of senile dementia with behavioral and psychological symptoms[Medical Science]. I Shanghai Jiaotong Univ 2017;37:398-402.

68 Orrell M, Hancock G, Hoe J, Woods B, Livingston G, Challis D. A cluster randomised controlled trial to reduce the unmet needs 
of people with dementia living in residential care. Int J Geriatr Psychiatry 2007;22:1127-34. doi:10.1002/gps.1801

69 Chapman DG, Toseland RW. Effectiveness of advanced illness care teams for nursing home residents with dementia. Soc Work 2007;52:321-9. doi:10.1093/sw/52.4.321

70 Meeuwsen EJ, Melis RJ, Van Der Aa GC, et al. Effectiveness of dementia follow-up care by memory clinics or general practitioners: randomised controlled trial. BMJ 2012;344:e3086. doi:10.1136/ bmj.e3086

71 Lu S-p, Zhang Y-h, Xu Y-n, et al. Hospital-community-family wholecourse nursing modes for patients with Alzheimer disease. Chinese Journal of Clinical Rehaiblitation 2005;9:70-3.

72 Lawton MP, Van Haitsma K, Klapper J, Kleban MH, Katz IR, Corn J. A stimulation-retreat special care unit for elders with dementing illness. Int Psychogeriatr 1998;10:379-95. doi:10.1017/ S104161029800547X

73 Zwijsen SA, Smalbrugge M, Eefsting JA, et al. Coming to grips with challenging behavior: a cluster randomized controlled trial on the effects of a multidisciplinary care program for challenging behavior in dementia. J Am Med Dir Assoc 2014;15:531.

74 Fernández-Calvo B, Contador I, Ramos F, Olazarán J, Mograbi DC, Morris RG. Effect of unawareness on rehabilitation outcome in a randomised controlled trial of multicomponent intervention for patients with mild Alzheimer's disease. Neuropsychol Rehabil 2015;25:448-77. doi:10.1080/09602011.2014.948461

75 Wenborn J, Challis D, Head J, et al. Providing activity for people with dementia in care homes: a cluster randomised controlled trial. Int J Geriatr Psychiatry 2013;28:1296-304. doi:10.1002/gps.3960

76 Kwok T, Lam L, Chung J. Case management to improve quality of life of older people with early dementia and to reduce caregiver burden. Hong Kong Med I 2012;18(Suppl 6):4-6.

77 Gitlin LN, Winter L, Burke J, Chernett N, Dennis MP, Hauck WW. Tailored activities to manage neuropsychiatric behaviors in persons with dementia and reduce caregiver burden: a randomized pilot study. Am J Geriatr Psychiatry 2008;16:229-39. doi:10.1097/01. JGP.0000300629.35408.94

78 Graff MJ, Vernooij-Dassen MJ, Thijssen M, Dekker J, Hoefnagels WH, Olderikkert MG. Effects of community occupational therapy on quality of life, mood, and health status in dementia patients and their caregivers: a randomized controlled trial. / Gerontol A Biol Sci Med Sci 2007;62:1002-9. doi:10.1093/gerona/62.9.1002

79 Bailey EM, Stevens AB, LaRocca MA, Scogin F. A Randomized Controlled Trial of a Therapeutic Intervention for Nursing Home Residents With Dementia and Depressive Symptoms. J Appl Gerontol 2017;36:895-908. doi:10.1177/0733464815627956

80 O'Shea E, Devane D, Cooney A, et al. The impact of reminiscence on the quality of life of residents with dementia in long-stay care. Int J Geriatr Psychiatry 2014;29:1062-70. doi:10.1002/gps.4099

81 Tadaka E, Kanagawa K. A randomized controlled trial of a group care program for community-dwelling elderly people with dementia. Jpn Nurs Sci 2004;1:19-25. doi:10.1111/j.1742-7924.2004.00006.x

82 Van Bogaert P, Van Grinsven R, Tolson D, Wouters K, Engelborghs $\mathrm{S}$, Van der Mussele S. Effects of SolCos model-based individual reminiscence on older adults with mild to moderate dementia due to Alzheimer disease: a pilot study. J Am Med Dir Assoc 2013:14:528.

83 Woods RT, Bruce E, Edwards RT, et al. REMCARE: reminiscence groups for people with dementia and their family caregivers - effectiveness and cost-effectiveness pragmatic multicentre randomised trial. Health Technol Assess 2012:16:1-116. doi:10.3310/hta16480

84 Wang JJ. Group reminiscence therapy for cognitive and affective function of demented elderly in Taiwan. Int / Geriatr Psychiatry 2007;22:1235-40. doi:10.1002/gps.1821

85 Lök N, Bademli K, Selçuk-Tosun A. The effect of reminiscence therapy on cognitive functions, depression, and quality of life in Alzheimer patients: Randomized controlled trial. Int J Geriatr Psychiatry 2019;34:47-53. doi:10.1002/gps.4980

86 Chang W, Lee J. The Effect of Group Reminiscence therapy on Depression, Quality of Life and Social Behavior of Patient with Dementia. Korean Journal of Gerontological Social Welfare 2006;34:239-69.

87 Goldwasser AN, Auerbach SM, Harkins SW. Cognitive, affective, and behavioral effects of reminiscence group therapy on demented elderly. Int J Aging Hum Dev 1987;25:209-22. doi:10.2190/8UX868VC-RDYF-VK4F

88 Haight BK, Gibson F, Michel Y. The Northern Ireland life review/ life storybook project for people with dementia. Alzheimers Dement 2006;2:56-8. doi:10.1016/j.jalz.2005.12.003

89 Morgan S, Woods R. Life Review with People with Dementia in Care Homes: A Preliminary Randomized Controlled Trial. Nonpharmacol Ther Dement 2009;1:1-17

90 Li M, Lyu JH, Zhang Y, et al. Efficacy of Group Reminiscence Therapy on Cognition, Depression, Neuropsychiatric Symptoms, and Activities of Daily Living for Patients With Alzheimer Disease. J Geriatr Psychiatry Neurol 2020;33:272-81. doi:10.1177/0891988719882099
91 Van Bogaert P, Tolson D, Eerlingen R, et al. SolCos model-based individual reminiscence for older adults with mild to moderate dementia in nursing homes: a randomized controlled intervention study. J Psychiatr Ment Health Nurs 2016;23:568-75. doi:10.1111/ jpm.12336

92 Amieva H, Robert PH, Grandoulier AS, et al. Group and individual cognitive therapies in Alzheimer's disease: the ETNA3 randomized trial. Int Psychogeriatr 2016;28:707-17. doi:10.1017/ S1041610215001830

93 Pérez-Ros P, Cubero-Plazas L, Mejías-Serrano T, Cunha C, MartínezArnau FM. Preferred Music Listening Intervention in Nursing Home Residents with Cognitive Impairment: A Randomized Intervention Study. I Alzheimers Dis 2019;70:433-42. doi:10.3233/JAD-190361

94 Chu H, Yang CY, Lin Y, et al. The impact of group music therapy on depression and cognition in elderly persons with dementia: a randomized controlled study. Biol Res Nurs 2014;16:209-17. doi:10.1177/1099800413485410

95 Lin Y, Chu H, Yang CY, et al. Effectiveness of group music intervention against agitated behavior in elderly persons with dementia. Int J Geriatr Psychiatry 2011;26:670-8. doi:10.1002/gps.2580

96 Raglio A, Bellandi D, Baiardi P, et al. Effect of Active Music Therapy and Individualized Listening to Music on Dementia: A Multicenter Randomized Controlled Trial. J Am Geriatr Soc 2015;63:1534-9. doi:10.1111/jgs.13558

97 Raglio A, Oasi O, Gianotti M, et al. Effects of music therapy on psychological symptoms and heart rate variability in patients with dementia. A pilot study. Curr Aging Sci 2010;3:242-6. doi:10.2174/ 1874609811003030242

98 Sakamoto M, Ando H, Tsutou A. Comparing the effects of different individualized music interventions for elderly individuals with severe dementia. Int Psychogeriatr 2013;25:775-84. doi:10.1017/ S1041610212002256

$99 \mathrm{An} \mathrm{H}$, Choi B, Park KW, et al. The Effect of Escitalopram on Mood and Cognition in Depressive Alzheimer's Disease Subjects. J Alzheimers Dis 2017;55:727-35. doi:10.3233/JAD-160225

100 de Vasconcelos Cunha UG, Lopes Rocha F, Avila de Melo R, et al. A placebo-controlled double-blind randomized study of venlafaxine in the treatment of depression in dementia. Dement Geriatr Cogn Disord 2007;24:36-41. doi:10.1159/000102570

101 Katona CL, Hunter BN, Bray J. A double-blind comparison of the efficacy and safely of paroxetine and imipramine in the treatment of depression with dementia. Int J Geriatr Psychiatry 1998;13:100 8. doi:10.1002/(SICI)1099-1166(199802)13:2く100::AIDGPS738>3.0.CO;2-

102 Lyketsos CG, DelCampo L, Steinberg M, et al. Treating depression in Alzheimer disease: efficacy and safety of sertraline therapy, and the benefits of depression reduction: the DIADS. Arch Gen Psychiatry 2003;60:737-46. doi:10.1001/archpsyc.60.7.737

103 Magai C, Kennedy G, Cohen Cl, Gomberg D. A controlled clinical trial of sertraline in the treatment of depression in nursing home patients with late-stage Alzheimer's disease. Am J Geriatr Psychiatry 2000;8:66-74. doi:10.1097/00019442-20000200000009

104 Mokhber N, Abdollahian E, Soltanifar A, et al. Comparison of sertraline, venlafaxine and desipramine effects on depression, cognition and the daily living activities in Alzheimer patients. Pharmacopsychiatry 2014;47:131-40. doi:10.1055/s-0034-1377041

105 Nyth AL, Gottfries CG, Lyby K, et al. A controlled multicenter clinical study of citalopram and placebo in elderly depressed patients with and without concomitant dementia. Acta Psychiatr Scand 1992;86:138-45. doi:10.1111/j.1600-0447.1992. tb03242.x

106 Petracca GM, Chemerinski E, Starkstein SE. A double-blind, placebocontrolled study of fluoxetine in depressed patients with Alzheimer's disease. Int Psychogeriatr 2001;13:233-40. doi:10.1017/ S104161020100761X

107 Petracca G, Tesón A, Chemerinski E, Leiguarda R, Starkstein SE. A double-blind placebo-controlled study of clomipramine in depressed patients with Alzheimer's disease. / Neuropsychiatry Clin Neurosci 1996;8:270-5. doi:10.1176/jnp.8.3.270

108 Rosenberg PB, Drye LT, Martin BK, et al, DIADS-2 Research Group. Sertraline for the treatment of depression in Alzheimer disease. Am J Geriatr Psychiatry 2010;18:136-45. doi:10.1097/ GP.0b013e3181c796eb

109 Taragano FE, Lyketsos CG, Mangone CA, Allegri RF, Comesaña-Diaz E. A double-blind, randomized, fixed-dose trial of fluoxetine vs. amitriptyline in the treatment of major depression complicating Alzheimer's disease. Psychosomatics 1997;38:246-52. doi:10.1016/S0033-3182(97)71461-0

110 Williams CL, Tappen RM. Exercise training for depressed older adults with Alzheimer's disease. Aging Ment Health 2008;12:72-80. doi:10.1080/13607860701529932

111 Teri L, Logsdon RG, Uomoto J, McCurry SM. Behavioral treatment of depression in dementia patients: a controlled clinical trial. J 
Gerontol B Psychol Sci Soc Sci 1997;52:159-66. doi:10.1093/ geronb/52B.4.P159

112 Verkaik R, Francke AL, van Meijel B, Spreeuwenberg PM, Ribbe MW, Bensing JM. The effects of a nursing guideline on depression in psychogeriatric nursing home residents with dementia. Int J Geriatr Psychiatry 2011;26:723-32. doi:10.1002/gps.2586

113 Lanza G, Centonze SS, Destro G, et al. Shiatsu as an adjuvant therapy for depression in patients with Alzheimer's disease: A pilot study. Complement Ther Med 2018;38:74-8. doi:10.1016/j. ctim.2018.04.013

114 Kiosses DN, Rosenberg PB, McGovern A, Fonzetti P, Zaydens H, Alexopoulos GS. Depression and Suicidal Ideation During Two Psychosocial Treatments in Older Adults with Major Depression and Dementia. J Alzheimers Dis 2015;48:453-62. doi:10.3233/JAD-150200

115 Bruvik FK, Allore HG, Ranhoff AH, Engedal K. The effect of psychosocial support intervention on depression in patients with dementia and their family caregivers: an assessorblinded randomized controlled trial. Dement Geriatr Cogn Dis Extra 2013;3:386-97. doi:10.1159/000355912

116 Noone D. The Impact of Mindfulness Based Cognitive Therapy Group for Depression in People with Dementia attending Memory Clinics: A Feasibility Randomised Controlled Trial. University College London, 2017.

117 McSweeney K, Jeffreys A, Griffith J, Plakiotis C, Kharsas R, O'Connor DW. Specialist mental health consultation for depression in Australian aged care residents with dementia: a cluster randomized trial. Int) Geriatr Psychiatry 2012:27:1163-71. doi:10.1002/gps.376

118 Erdal A, Flo E, Aarsland D, Ballard C, Slettebo DD, Husebo BS Efficacy and Safety of Analgesic Treatment for Depression in People with Advanced Dementia: Randomised, Multicentre, Double-Blind, Placebo-Controlled Trial (DEP.PAIN.DEM). Drugs Aging 2018;35:54558. doi:10.1007/s40266-018-0546-2

119 Woods B, Aguirre E, Spector AE, Orrell M. Cognitive stimulation to improve cognitive functioning in people with dementia. Cochrane Database Syst Rev 2012;(2):CD005562. doi:10.1002/14651858. CD005562.pub2

120 Woods B, O'Philbin L, Farrell EM, Spector AE, Orrell M. Reminiscence therapy for dementia. Cochrane Database Syst Rev 2018;3:CD001120.

121 Dudas R, Malouf R, McCleery J, Dening T. Antidepressants for treating depression in dementia. Cochrane Database Syst Rev 2018;8:CD003944.

122 Gitlin LN, Rose K. Factors associated with caregiver readiness to use nonpharmacologic strategies to manage dementia-related behavioral symptoms. Int J Geriatr Psychiatry 2014;29:93-102. doi:10.1002 gps.3979

123 Graff MJ, Adang EM, Vernooij-Dassen MJ, et al. Community occupational therapy for older patients with dementia and their care givers: cost effectiveness study. BMJ 2008;336:134-8. doi:10.1136/ bmj.39408.481898.BE

124 NICE. Dementia: assessment, management and support for people living with dementia and their carers. NICE Guideline [NG97]. 2018. https://www.nice.org.uk/guidance/ng97

Supplementary information: additional tables 1-9, figures 1-3, and references 